\title{
Detection of hyperoxaemia in neonates: data from three new pulse oximeters
}

\author{
B Bohnhorst, C S Peter, C F Poets
}

Arch Dis Child Fetal Neonatal Ed 2002;87:F217-F2 19

See end of article for authors' affiliations

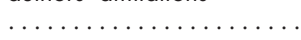

Correspondence to: Professor Poets, Department of Neonatology, University of Tübingen, Calwerstr 7,

D-72070 Tübingen

Germany;

Christian-F.Poets@

med.uni-tuebingen.de

Accepted 26 May 2002
Aim: To determine the sensitivity and specificity of three newly developed pulse oximeters in the detection of hyperoxaemia, defined as an arterial partial pressure of oxygen $\left(\mathrm{PaO}_{2}\right)$ of $>80 \mathrm{~mm} \mathrm{Hg}$. Methods: $\mathrm{SpO}_{2}$ readings from three oximeters (Agilent Viridia (AgV), Masimo SET (MaS), Nellcor Oxismart ( $\mathrm{NeO}$ )) were documented in 56 infants (median gestational age at birth 35.5 weeks, range 24-41) whenever an arterial blood gas was taken for clinical purposes. Blood samples were analysed within one minute in a Radiometer ABL 505 blood gas analyser and OSM3 co-oximeter.

Results: Between 280 and 291 blood gases were analysed for each instrument; 105-112 showed a $\mathrm{PaO}_{2}>80 \mathrm{~mm} \mathrm{Hg}$. At an upper alarm limit of 95\%, the three instruments detected hyperoxaemia with 93-95\% sensitivity. Specificity at this alarm level ranged from 26 to $45 \%$. The mean (SD) difference between arterial oxygen saturation and $\mathrm{SpO}_{2}$ (bias) was -0.25 (2.5)\% for $\mathrm{AgV},-0.06$ (2.5)\% for MaS, and $-0.91(2.6) \%$ for $\mathrm{NeO}$ ( $p<0.01, \mathrm{NeO} \vee \mathrm{AgV}$ and $\mathrm{MaS}$ ).

Conclusion: These instruments detected hyperoxaemia with sufficient sensitivity at an upper alarm limit of $95 \%$, but showed differences in their specificity, which was probably related to differences in measurement bias.
$\mathrm{D}$ etermination of the partial pressure of oxygen in arterial blood $\left(\mathrm{PaO}_{2}\right)$ is regarded as the optimum method for assessing oxygenation. ${ }^{1}$ In clinical practice, however, oxygenation is increasingly monitored by pulse oximetry, mainly because this technique provides immediate, continuous, and non-invasive information without the need for calibration or sensor replacement. ${ }^{1}$ Nevertheless, it has two major disadvantages: a high rate of false alarms, most of which are caused by motion artefact, and a reduced sensitivity to hyperoxaemia. ${ }^{2}$ The latter is due to the shape of the oxygen dissociation curve, where large changes in the upper range of $\mathrm{PaO}_{2}$ are associated with small changes in arterial oxygen saturation $\left(\mathrm{SaO}_{2}\right)$. This is unfortunate, because reliable detection of hyperoxaemia, usually defined as a $\mathrm{PaO}_{2}>80 \mathrm{~mm}$ $\mathrm{Hg}$, is crucial for the avoidance of retinopathy of prematurity and other oxygen related diseases. ${ }^{3-5}$ As software algorithms and probe calibrations differ between instruments and sensors, there may be differences in the upper alarm limit used with an individual manufacturer's pulse oximeter to optimally detect hyperoxaemia. ${ }^{16}$

Recent developments in pulse oximetry have resulted in a dramatic reduction in false alarm rates, ${ }^{7}$ which makes these instruments particularly attractive for the neonatal intensive care unit. Nothing, however, is known about their ability to detect hyperoxaemia. We set out to determine the sensitivity and specificity of three recently available pulse oximeters in the detection of hyperoxaemia.

\section{PATIENTS AND METHODS}

Fifty six term and preterm infants (33 boys) were enrolled after informed parental consent had been obtained. These infants had been admitted to the neonatal intensive care unit at Hannover Medical School for various reasons (extreme prematurity (18), congenital malformations (21), metabolic disorders (6), respiratory failure in near term infants (7), asphyxia (3), and morbus haemolyticus neonatorum (1)) and had indwelling arterial lines (right or left radial artery) for clinical reasons. Their median gestational age was 35.5 weeks (range 24-41), birth weight 2480 g (range 370-4680), age at study 6 days (range 1-149), and study weight 2680 g (range 430-5800). Forty two infants were mechanically ventilated, and five received continuous positive airway pressure through a nasopharyngeal tube; 48 infants received additional inspired oxygen. Infants with a patent arterial duct, as shown by colour Doppler echocardiography, who had a preductal arterial line were not enrolled. In addition to standard monitoring equipment, which included a pulse oximeter, 46 infants had one and 10 infants had two additional sensors attached to a hand and/or foot; the clinical characteristics of the infants in these subgroups were similar. Instruments used in this study were the Agilent Viridia M3 (AgV; software version B; Agilent, Böblingen, Germany), Masimo SET (MaS; software version 1.13; Masimo, Irvine, California, USA), and Nellcor N3000 Oxismart (NeO; software version 3.04, Mallinckrodt, Pleasanton, California, USA). Sensors used were the Nellcor N20 with $\mathrm{NeO}$ and $\mathrm{AgV}$ and the Masimo NeoPT with MaS. Care was taken that sensors had good contact with the skin and were shielded against each other and ambient light by opaque foam wraps. Averaging times were 10 seconds for AgV, 8 seconds for MaS, and variable - that is, dependent on signal quality-for $\mathrm{NeO}$.

Whenever an arterial blood sample was taken for clinical purposes, the $\mathrm{SpO}_{2}$ readings on the oximeters were recorded at the precise moment the blood was drawn into the syringe for analysis. Measurements were not timed specifically to include high $\mathrm{PaO}_{2}$ values or to exclude periods with motion and/or differences between pulse and heart rate, ${ }^{6}$ but $\mathrm{Spo}_{2}$ readings had to be stable for at least 20 seconds before the arterial blood sample was drawn; this was to exclude the possibility that any potential differences between instruments were caused by their variable averaging times. Blood samples were analysed within one minute: $\mathrm{PaO}_{2}$ was measured with a standard blood gas analyser (Radiometer ABL 505; Radiometer, Copenhagen,

Abbreviations: AgV, Agilent Viridia; MaS, Masimo SET; NeO, Nellcor Oxismart; $\mathrm{PaO}_{2}$, arterial partial pressure of oxygen; $\mathrm{SaO}_{2}$, arterial oxygen saturation; $\mathrm{SpO}_{2}$, pulse oximeter saturation. 

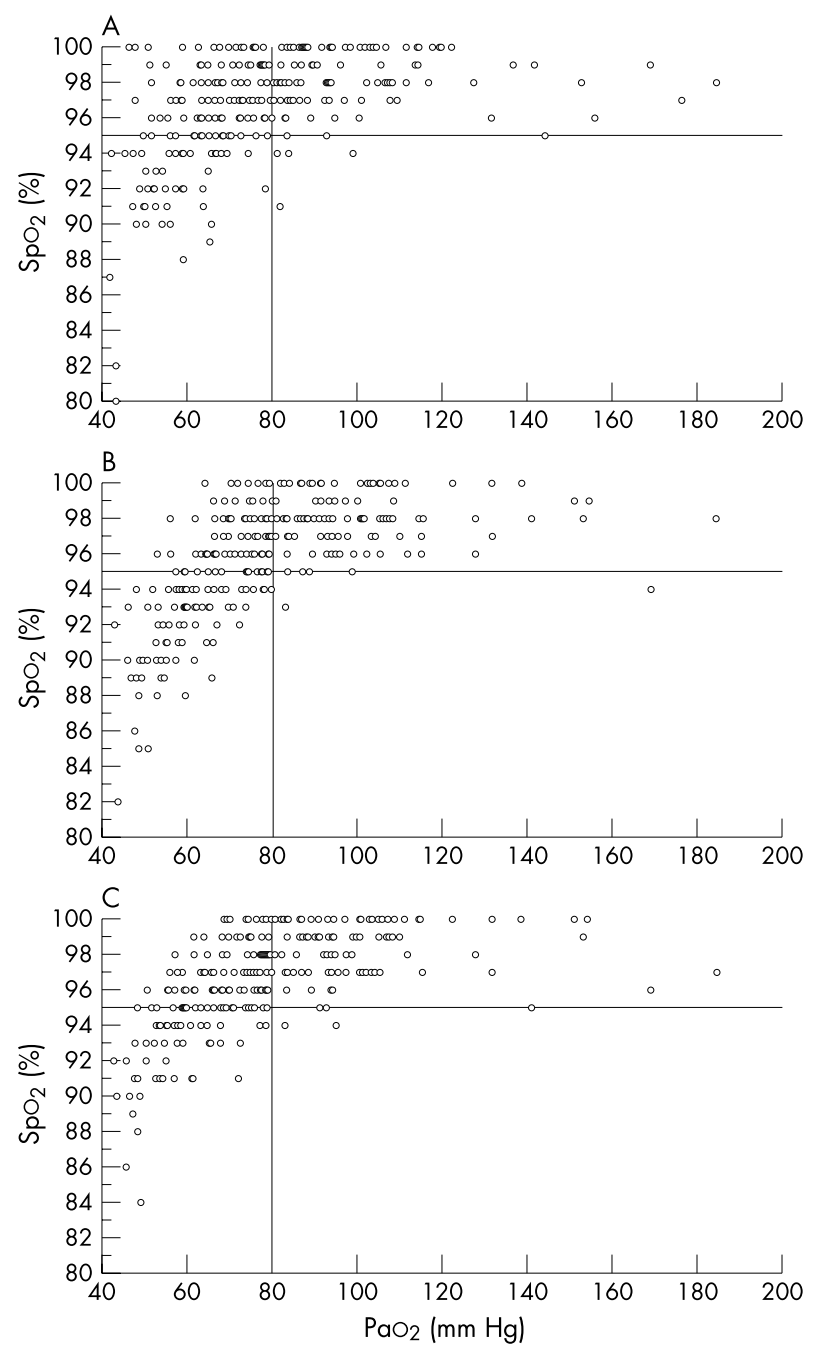

Figure $1 \mathrm{PaO}_{2}$, plotted against $\mathrm{SpO}_{2}$, for Agilent Viridia $(\mathrm{A})$, Masimo SET (B), and Nellcor Oxismart (B). The vertical lines indicate the threshold used to define hyperoxaemia, the horizontal ones the alarm limit at which the instruments detected at least $93 \%$ of hyperoxaemic episodes.

Denmark), and functional $\mathrm{SaO}_{2}$ with a co-oximeter (Radiometer OSM 3). Co-oximeter measurements were corrected for fetal haemoglobin. $\mathrm{SaO}_{2}$ values were plotted against the difference between arterial and pulse oximeter saturation measurements $\left(\mathrm{SaO}_{2}-\mathrm{SpO}_{2}\right)$, and the mean (bias) and standard deviations (precision) of these differences calculated for each instrument. ${ }^{89}$ Sensitivity was calculated as the proportion of instances with a $\mathrm{PaO}_{2}>80 \mathrm{~mm} \mathrm{Hg}$ that were associated with an $\mathrm{SpO}_{2}$ value above the threshold, divided by all instances with $\mathrm{PaO}_{2}>80 \mathrm{~mm} \mathrm{Hg}$. Specificity was calculated as the proportion of $\mathrm{PaO}_{2}$ readings $\leqslant 80 \mathrm{~mm} \mathrm{Hg}$ associated with an $\mathrm{SpO}_{2}$ value below the threshold, divided by the number of all instances with a $\mathrm{PaO}_{2} \leqslant 80 \mathrm{~mm} \mathrm{Hg}$. Statistical analysis was performed using the two sided $t$ test. The study protocol was approved by the ethics committee of Hannover Medical School.

\section{RESULTS}

A total of $280 \mathrm{Spo}_{2} / \mathrm{SaO}_{2} / \mathrm{PaO}_{2}$ determinations were performed for $\mathrm{AgV}$, and 291 each for MaS and NeO; 105 (112 for AgV) in 27 (24) patients showed a $\mathrm{PaO}_{2}>80 \mathrm{~mm} \mathrm{Hg}$ (fig l). A median of 10 measurements (range 2-15) was documented in each infant, with a median of three measurements (range 1-13) showing a $\mathrm{PaO}_{2}>80 \mathrm{~mm} \mathrm{Hg}$. Table 1 shows sensitivity and specificity at various potential upper alarm limits. At an upper alarm limit of $95 \%$, all three instruments detected $93-95 \%$ of hyperoxaemic episodes - that is, sensitivity to hyperoxaemia was comparable between instruments. Specificity at this threshold value, however, was more variable, ranging from $26 \%(\mathrm{NeO})$ to $45 \%$ (MaS).

The two highest $\mathrm{PaO}_{2}$ values that were $>80 \mathrm{~mm} \mathrm{Hg}$, but associated with an $\mathrm{Spo}_{2} \leqslant 95 \%$ (false negative for hyperoxaemia) were 144 and $92 \mathrm{~mm} \mathrm{Hg}$ for AgV, 169 and $98 \mathrm{~mm} \mathrm{Hg}$ for $\mathrm{MaS}$, and 141 and $95 \mathrm{~mm} \mathrm{Hg}$ for $\mathrm{NeO}$. The lowest $\mathrm{PaO}_{2}$ with $\mathrm{SpO}_{2}>95 \%$ (false positive for hyperoxaemia) was $46 \mathrm{~mm} \mathrm{Hg}$ for $\mathrm{AgV}, 56 \mathrm{~mm} \mathrm{Hg}$ for $\mathrm{MaS}$, and $50 \mathrm{~mm} \mathrm{Hg}$ for $\mathrm{NeO}$ (fig l).

Measurement precision, defined as the standard deviation of the difference between $\mathrm{SaO}_{2}$ and $\mathrm{Spo}_{2}$, was similar between instruments (2.5\% for both $\mathrm{AgV}$ and $\mathrm{MaS}, 2.6 \%$ for $\mathrm{NeO}$ ), while bias was smaller with the MaS (mean, $-0.06 \%$ ) and AgV $(-0.25 \%)$ than with the $\mathrm{NeO}$ instrument $(-0.91 \%, \mathrm{p}<0.01$ for $\mathrm{NeO} v \mathrm{AgV}$ and $\mathrm{MaS})$.

\section{DISCUSSION}

The three pulse oximeters investigated in this study were chosen because they were shown to $^{7}$ or purportedly have a relatively low false alarm rate, making them potentially interesting for use in neonates, in whom false alarms are a major problem. ${ }^{2}$ Avoidance of hyperoxaemia is particularly important in this age group. As previous studies have shown major differences in the upper alarm limit that has to be used if priority is given to the avoidance of hyperoxaemia, ${ }^{1610^{11}}$ we wanted to know whether such differences still exist with current instruments. We found that all three instruments detected hyperoxaemia, defined as a $\mathrm{PaO}_{2}>80 \mathrm{~mm} \mathrm{Hg}$, with sufficient sensitivity (93-95\%) if the upper alarm limit was set at $95 \%$.

Because we aimed to have a substantial proportion of hyperoxaemic values, we did not restrict our study to preterm infants, as did Bucher et al, ${ }^{6}$ but also included term infants. As $\mathrm{SaO}_{2}$ measurements were corrected for the proportion of fetal haemoglobin, and pulse oximeters are not influenced by fetal haemoglobin, we are confident that the decision to include

Table 1 Sensitivity and specificity at various potential upper alarm limits

\begin{tabular}{|c|c|c|c|c|c|c|c|c|}
\hline \multirow{2}{*}{$\begin{array}{l}\text { Upper alarm } \\
\text { limit (\%) }\end{array}$} & \multicolumn{2}{|c|}{ Agilent Viridia } & \multicolumn{2}{|c|}{ Masimo SET } & \multicolumn{2}{|c|}{ Nellcor Oxismart } & \multicolumn{2}{|c|}{ Radiometer OSM3 } \\
\hline & Sensitivity & Specificity & Sensitivity & Specificity & Sensitivity & Specificity & Sensitivity & Specificity \\
\hline 92 & 0.99 & 0.12 & 1.00 & 0.16 & 1.00 & 0.10 & 1.00 & 0.23 \\
\hline 93 & 0.99 & 0.18 & 0.99 & 0.21 & 1.00 & 0.12 & 1.00 & 0.30 \\
\hline 94 & 0.96 & 0.21 & 0.98 & 0.31 & 0.98 & 0.18 & 0.99 & 0.38 \\
\hline 95 & 0.93 & 0.30 & 0.94 & 0.45 & 0.95 & 0.26 & 0.99 & 0.46 \\
\hline 96 & 0.86 & 0.43 & 0.83 & 0.54 & 0.90 & 0.45 & 0.95 & 0.62 \\
\hline 97 & 0.72 & 0.55 & 0.68 & 0.72 & 0.70 & 0.63 & 0.87 & 0.79 \\
\hline 98 & 0.48 & 0.69 & 0.36 & 0.82 & 0.58 & 0.74 & 0.64 & 0.92 \\
\hline 99 & 0.30 & 0.81 & 0.23 & 0.93 & 0.34 & 0.85 & 0.25 & 0.98 \\
\hline
\end{tabular}


term infants did not affect our results. Also, the number of measurements varied between infants. This was because blood gases were only taken for clinical purposes, and arterial lines were removed at the discretion of the attending neonatologist. There was nothing to suggest, however, that this decision in any way biased our results.

The sensitivity of these pulse oximeters was within the same range as that of some conventional instruments, ${ }^{6}{ }^{10-12}$ with only minimal differences between instruments. This is probably due to the fact that all instruments measure functional rather than fractional oxygen saturation, which is in contrast with an earlier study, ${ }^{6}$ which found that an instrument that measured fractional saturation had to be used with an upper alarm limit of $88 \%$ if hyperoxaemia were to be detected reliably. With regard to specificity, however, the MaS seemed to perform better than the other two instruments, which may be related to differences in measurement bias. Although these differences were small $(<1 \%)$, they may still be relevant, as small changes in $\mathrm{SaO}_{2}$ may be associated with large changes in $\mathrm{PaO}_{2}$ in the hyperoxic range.

As shown in table 1 , both sensitivity and specificity depend on the alarm limit used. Sensitivity can be increased by decreasing the upper alarm limit, but the specificity, which is already low, will then decrease even further. This carries the risk of keeping infants hypoxaemic if priority is given to the avoidance of hyperoxaemia. This is because a wide range of $\mathrm{PaO}_{2}$ values may be associated with an $\mathrm{SpO}_{2}$ above the upper alarm limit (fig 1). In this study, the lowest $\mathrm{PaO}_{2}$ value measured with an $\mathrm{Spo}_{2}>95 \%$, however, was always above 45 $\mathrm{mm} \mathrm{Hg}$, which is somewhat reassuring.

Although our findings largely reflect blood physiology, i.e. the shape of the $\mathrm{O}_{2}$ dissociation curve, one might expect that the new generation instruments investigated here would have performed better than their first generation counterparts. Their major strength, however, is their improved handling of conditions with low signal to noise ratios, for which they apply frequency domain analysis $(\mathrm{AgV})$, adaptive filtering $(\mathrm{NeO})$, or a combination of frequency and time domain analysis and adaptive filtering (MaS). ${ }^{13}$ Such conditions, however, although not specifically excluded, occur comparatively rarely and are thus unlikely to have significantly affected our results.

A principal problem with a study validating medical instruments is that software algorithms are constantly updated by manufacturers. For example, Nellcor's Oxismart technology has already been replaced by Oxismart/XL, and Masimo had two major software upgrades since initiation of this study. All three manufacturers, however, assured us that, although handling of motion and/or low perfusion has changed with these software upgrades, the "lookup tables" used for deriving the displayed saturation values from the red/infrared ratios that are actually measured have not.

In conclusion, this study has shown that all three pulse oximeters investigated are similarly sensitive in the detection of hyperoxaemia, but differ somewhat in their specificity, probably reflecting differences in measurement bias. Nevertheless, despite these encouraging results, we do not recommend using pulse oximetry as the sole means of monitoring oxygenation in the neonatal intensive care unit. We must also warn against uncritically applying the definition used for hyperoxaemia in this study, although valid for preterm infants receiving additional inspired oxygen, to healthy neonates breathing room air at sea level, in whom both an $\mathrm{PaO}_{2}$ above $80 \mathrm{~mm} \mathrm{Hg}$ and an $\mathrm{Spo}_{2}$ above $95 \%$ are part of normal infant physiology. ${ }^{14} 15$

\section{ACKNOWLEDGEMENTS}

We are grateful to the medical and nursing staff of the neonatal intensive care unit at Hannover Medical School for their help with this study and to Agilent, Masimo, and Nellcor for providing the instruments investigated in this study.

\section{Authors' affiliations}

B Bohnhorst, C S Peter, Department of Neonatology and Pediatric Pulmonology, Hannover Medical School, Hannover, Germany C F Poets, Department of Neonatology, University Hospital, Tübingen, Germany

\section{REFERENCES}

1 Poets CF, Southall DP. Noninvasive monitoring of oxygenation in infants and children: practical considerations and areas of concern. Pediatrics 1994; 93:737-46.

2 Lawless ST. Crying wolf: false alarms in a pediatric intensive care unit. Crit Care Med 1994;22:981-5.

3 Hay WW. Physiology of oxygenation and its relation to pulse oximetry in neonates. J Perinatol 1987;7:309-19.

4 American Academy of Pediatrics, American College of Obstetricians and Gynecologists. Guidelines for perinatal care. 3rd ed. Elk Grove Village, IL: The Academy, 1992.

5 Flynn JT, Bancalari E, Snyder ES. A cohort study of transcutaneous oxygen tension and the incidence and severity of retinopathy of prematurity. N Engl J Med 1992;326:1050-80.

6 Bucher HU, Fanconi S, Baeckert $P$, et al. Hyperoxemia in newborn infants: detection by pulse oximetry. Pediatrics 1989;84:226-30.

7 Bohnhorst B, Poets CF. Major reduction in alarm frequency with a new pulse oximeter. Intensive Care Med 1998;24:277-8

8 Healy MJR. Diagnostic and screening tests and reference values. Arch Dis Child 1995;72:358-61

9 Poets CF, Seidenberg J, Wilken M, et al. Die Meßgenauigkeit des Kontron 7840, Nellcor N200, und Radiometer OXI3 Pulsoximeters bei Säuglingen und Kleinkindern. Klin Pädiatr 1993;205:107-10.

10 Paky F, Koeck CM. Pulse oximetry in ventilated preterm newborns: reliability of detection of hyperoxaemia and hypoxaemia, and feasibility of alarm settings. Acta Paediatr 1995;84:613-16.

11 Poets CF, Wilken M, Seidenberg J, et al. Reliability of a pulsoximeter in the detection of hyperoxemia. J Pediatr 1993;122:87-90.

12 Gupta R, Yoxall CW, Subedhar N, et al. Individualised pulse oximetry limits in neonatal intensive care. Arch Dis Child Fetal Neonatal Ed 1999;81:F194-6.

13 Jopling MW, Mannheimer PD, Bebout DE. Issues in the laboratory evaluation of pulse oximeter performance. Anesth Analg 2002:94:S62-8.

14 Koch G, Wendel H. Adjustment of arterial blood gases and acid base balance in the normal newborn infant during the first week of life. Bio Neonate 1968;12:136-61.

15 O'Brien LM, Stebbens VA, Poets CF, et al. Oxygen saturation during the first 24 hours of life. Arch Dis Child Fetal Neonatal Ed 2000;83:F35-8. 